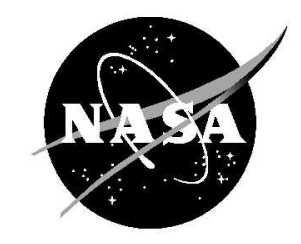

\title{
Solar Energy Systems for Lunar Oxygen Generation
}

Anthony J. Colozza

Analex Corporation, Cleveland, Ohio

Richard S. Heller

Massachusetts Institute of Technology, Cambridge, Massachusetts

Wayne A. Wong and Aloysius F. Hepp

Glenn Research Center, Cleveland, Ohio 


\section{NASA STI Program . . . in Profile}

Since its founding, NASA has been dedicated to the advancement of aeronautics and space science. The NASA Scientific and Technical Information (STI) program plays a key part in helping NASA maintain this important role.

The NASA STI Program operates under the auspices of the Agency Chief Information Officer. It collects, organizes, provides for archiving, and disseminates NASA's STI. The NASA STI program provides access to the NASA Aeronautics and Space Database and its public interface, the NASA Technical Reports Server, thus providing one of the largest collections of aeronautical and space science STI in the world. Results are published in both non-NASA channels and by NASA in the NASA STI Report Series, which includes the following report types:

- TECHNICAL PUBLICATION. Reports of completed research or a major significant phase of research that present the results of NASA programs and include extensive data or theoretical analysis. Includes compilations of significant scientific and technical data and information deemed to be of continuing reference value. NASA counterpart of peer-reviewed formal professional papers but has less stringent limitations on manuscript length and extent of graphic presentations.

- TECHNICAL MEMORANDUM. Scientific and technical findings that are preliminary or of specialized interest, e.g., quick release reports, working papers, and bibliographies that contain minimal annotation. Does not contain extensive analysis.

- CONTRACTOR REPORT. Scientific and technical findings by NASA-sponsored contractors and grantees.
- CONFERENCE PUBLICATION. Collected papers from scientific and technical conferences, symposia, seminars, or other meetings sponsored or cosponsored by NASA.

- SPECIAL PUBLICATION. Scientific, technical, or historical information from NASA programs, projects, and missions, often concerned with subjects having substantial public interest.

- TECHNICAL TRANSLATION. Englishlanguage translations of foreign scientific and technical material pertinent to NASA's mission.

Specialized services also include creating custom thesauri, building customized databases, organizing and publishing research results.

For more information about the NASA STI program, see the following:

- Access the NASA STI program home page at http://www.sti.nasa.gov

- E-mail your question via the Internet to help@ sti.nasa.gov

- Fax your question to the NASA STI Help Desk at $443-757-5803$

- Telephone the NASA STI Help Desk at 443-757-5802

- Write to: NASA Center for AeroSpace Information (CASI) 7115 Standard Drive Hanover, MD 21076-1320 


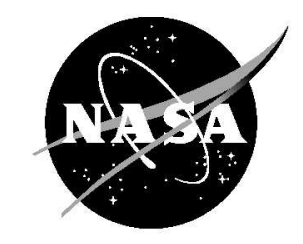

\section{Solar Energy Systems for Lunar Oxygen Generation}

Anthony J. Colozza

Analex Corporation, Cleveland, Ohio

Richard S. Heller

Massachusetts Institute of Technology, Cambridge, Massachusetts

Wayne A. Wong and Aloysius F. Hepp

Glenn Research Center, Cleveland, Ohio

Prepared for the

48th Aerospace Sciences Meeting

sponsored by the American Institute of Aeronautics and Astronautics

Orlando, Florida, January 4-7, 2010

National Aeronautics and

Space Administration

Glenn Research Center

Cleveland, Ohio 44135 


\section{Acknowledgments}

Richard S. Heller is grateful for support as a 2009 Summer Scholar by the Chickasaw Nation, Ada, Oklahoma. Anthony J. Colozza acknowledges support from the Exploration Technology Development Program,

Solar Concentrator Task.

This report contains preliminary findings, subject to revision as analysis proceeds.

Trade names and trademarks are used in this report for identification only. Their usage does not constitute an official endorsement, either expressed or implied, by the National Aeronautics and Space Administration.

Level of Review: This material has been technically reviewed by technical management.

Available from

NASA Center for Aerospace Information 7115 Standard Drive

Hanover, MD 21076-1320
National Technical Information Service 5301 Shawnee Road Alexandria, VA 22312

Available electronically at http://gltrs.grc.nasa.gov 


\title{
Solar Energy Systems for Lunar Oxygen Generation
}

\author{
Anthony J. Colozza \\ Analex Corporation \\ Cleveland, Ohio 44135 \\ Richard S. Heller \\ Massachusetts Institute of Technology \\ Cambridge, Massachusetts 02139 \\ Wayne A. Wong and Aloysius F. Hepp \\ National Aeronautics and Space Administration \\ Glenn Research Center \\ Cleveland, Ohio 44135
}

\begin{abstract}
An evaluation of several solar concentrator-based systems for producing oxygen from lunar regolith was performed. The systems utilize a solar concentrator mirror to provide thermal energy for the oxygen production process. Thermal energy to power a Stirling heat engine and photovoltaics are compared for the production of electricity. The electricity produced is utilized to operate the equipment needed in the oxygen production process. The initial oxygen production method utilized in the analysis is hydrogen reduction of ilmenite. Utilizing this method of oxygen production a baseline system design was produced. This baseline system had an oxygen production rate of $0.6 \mathrm{~kg} / \mathrm{hr}$ with a concentrator mirror size of $5 \mathrm{~m}$. Variations were performed on the baseline design to show how changes in the system size and process (rate) affected the oxygen production rate. An evaluation of the power requirements for a carbothermal lunar regolith reduction reactor has also been conducted. The reactor had a total power requirement between 8,320 to $9,961 \mathrm{~W}$ when producing $1000 \mathrm{~kg} / \mathrm{year}$ of oxygen. The solar concentrator used to provide the thermal power (over 82 percent of the total energy requirement) would have a diameter of less than $4 \mathrm{~m}$.
\end{abstract}

\section{Introduction}

The ability to produce oxygen is a key aspect of the successful human exploration and colonization of the lunar surface. Oxygen is required as a propellant reactant and is also needed to sustain a breathable atmosphere within habitation modules. Transporting oxygen from the Earth's surface is very costly and requires a sufficient stockpile to be housed on the lunar surface as a precaution in case there is a disruption with the supply from Earth. By producing the oxygen from material available on the lunar surface, the dependence on Earth resupply and its cost can be eliminated. In addition to the cost savings, utilizing available resources to produce oxygen is the first step toward a viable selfsustaining human presence on the lunar surface.

Oxygen is the most prevalent element on the lunar surface, about 45 percent of lunar regolith (Ref. 1). However, it is chemically locked up in various compounds that make up the regolith. There are a number of reactions and processes that have been devised which can break apart the regolith compounds and liberate the oxygen (Ref. 2). One common aspect of all of these processes is the need for heat to be added to the regolith. The most efficient method of achieving this heat addition is by direct heating of the regolith with concentrated solar energy.

This study examines two cases: a system that utilizes a solar concentrating mirror as a means of providing the thermal energy to heat the regolith and a Stirling heat engine to provide the electrical power to operate the processes involved in the production of oxygen. There is an inherent advantage in overall system efficiency and compact system design by providing direct thermal heating as well as power generation from a single concentrator mirror. The ultimate goal of this kind of compact arrangement would be the design of an autonomous, self-contained oxygen production system that can be deployed to the lunar surface and begin oxygen production without the need for human assembly. The other system employs a hybrid approach with photovoltaics to produce electrical energy. Greater design flexibility through choice of solar cell technology is gained through this more complex approach. 


\section{Nomenclature}

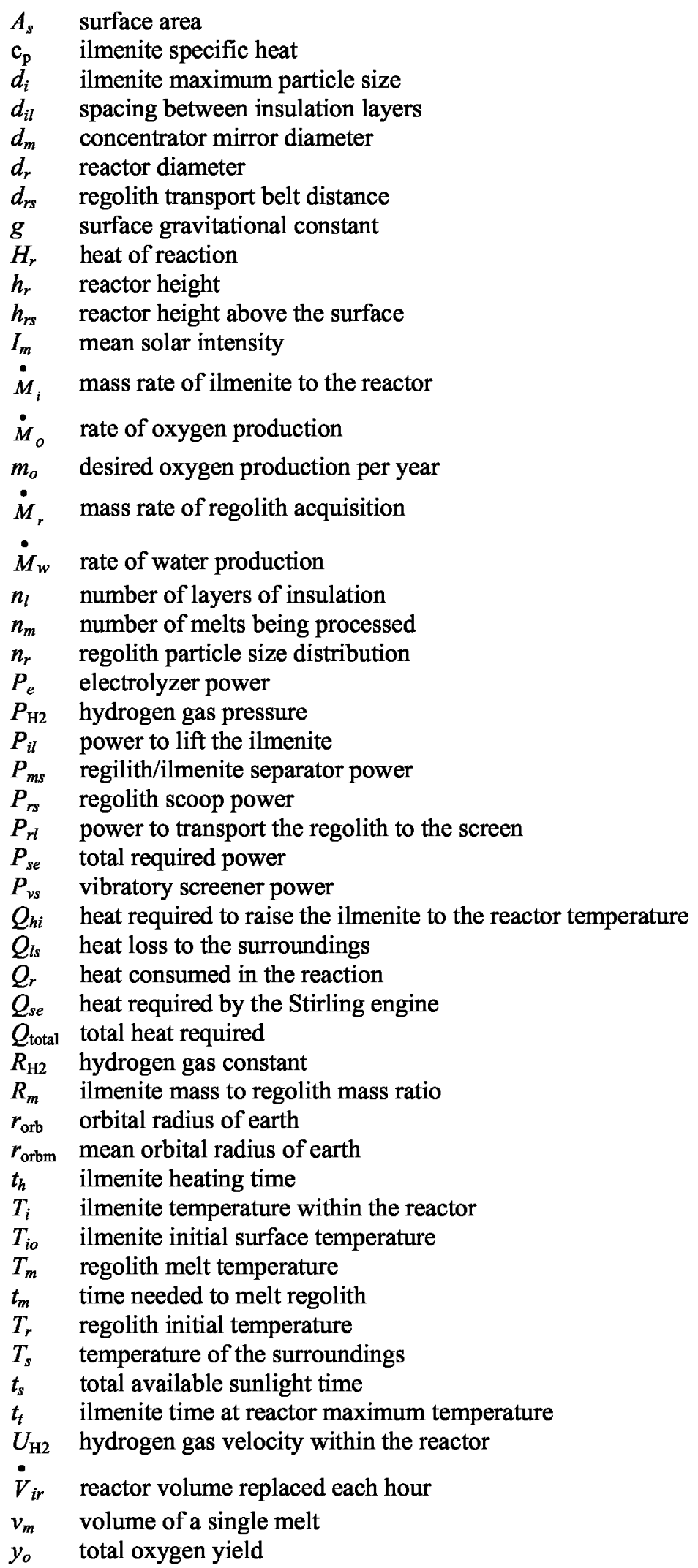




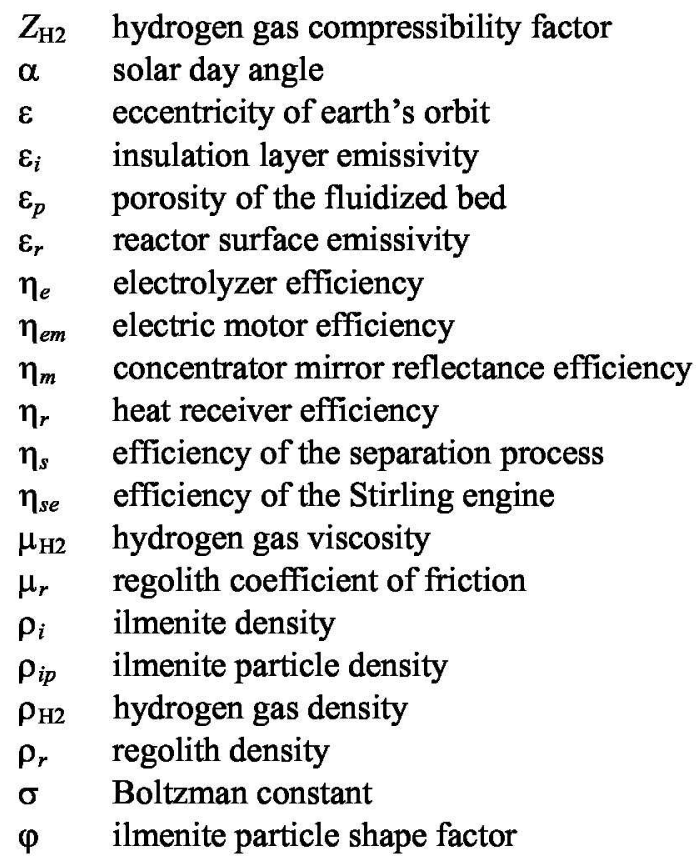

\section{The Lunar Environment}

The Moon (shown in Fig. 1) (Ref. 3) is a dry, crater-filled land with no appreciable atmosphere. The temperature difference from the sunlit areas to shadowed areas can exceed $300 \mathrm{~K}$. The surface is covered with a fine powdered regolith made from eons of bombardment by meteors, asteroids, and comets. The successful design and operation of a lunar oxygen production system within this harsh environment will require the system to leverage the advantages of the environment (such as abundant solar energy) and minimize the disadvantages (such as temperature extremes). From the solar availability to the amount of removable oxygen in the soil, the capabilities of this system will be based on how well it is adapted to these environmental conditions.

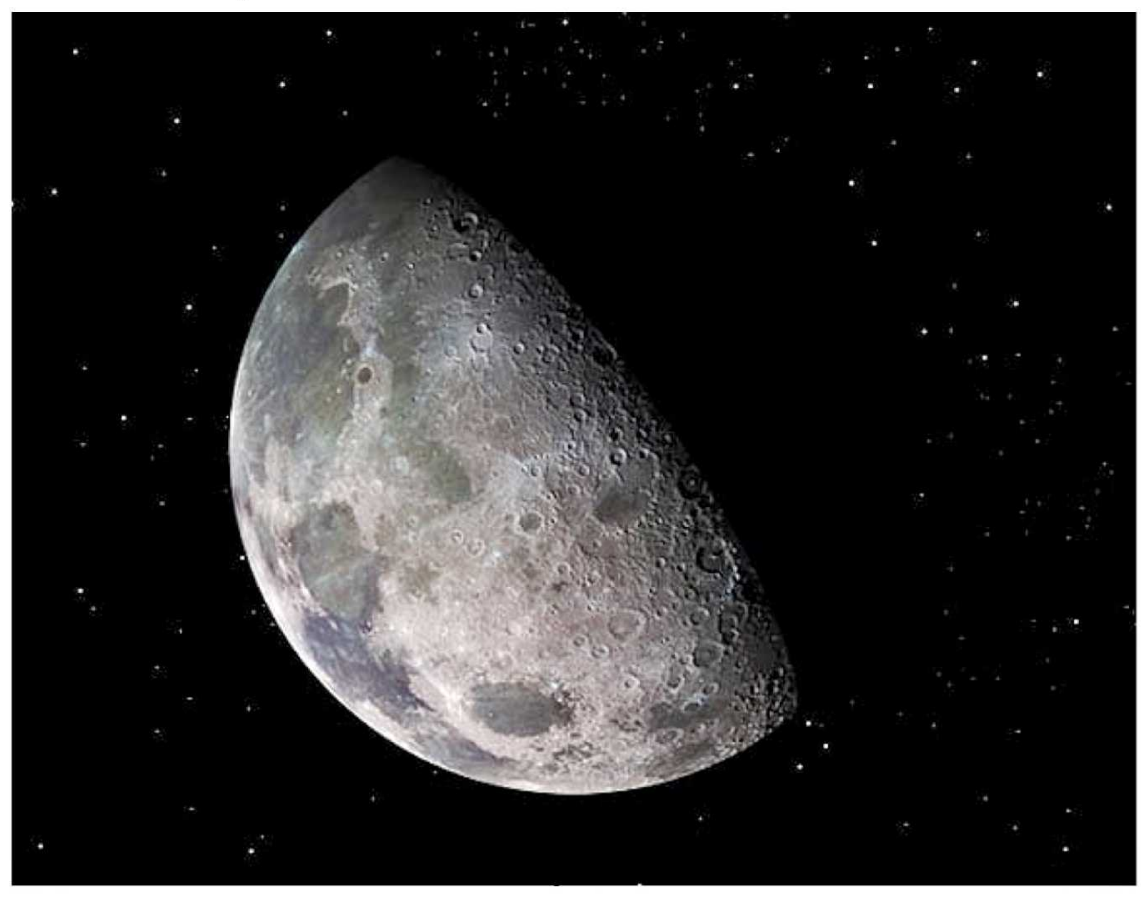

Figure 1.-Image of the Moon. 
There are two main types of terrain on the lunar surface, the highlands and the mare. The highlands are the older, brighter regions (as seen from Earth) of the lunar surface and are significantly cratered. The mare consist of darker regions which are basaltic lava flows. These areas can be seen in the topographic map of the lunar surface shown in Figure 2. The blue and purple regions are the lower-lying mare regions while the red, orange and yellow areas are the upper highland regions. The lunar regolith, which covers the surface of the Moon, consists of fragments of rocks, minerals and glass spherules formed when meteors or other bodies impacted the surface. The regolith thickness varies greatly with location on the lunar surface. In the mare the thickness can vary between 3 to $16 \mathrm{~m}$ whereas in the highlands it is at least $10 \mathrm{~m}$ thick (Ref. 1). The chemical or mineral composition of the regolith is similar to the underlying bedrock from which it was derived. There is little mixing of material between the highland and mare regions. The composition of the major materials (greater than 1 percent of the composition) in each of these regions is given in Table 1.

The regolith is composed of fine grains of the mineral compounds given in Table 1. The grain size of the regolith varies but consists mostly of particles less than $1 \mathrm{~mm}$ in diameter. This is similar in consistency to silt or fine sand (Ref. 1). Average regolith density $\left(\rho_{r}\right)$ is approximately $1000 \mathrm{~kg} / \mathrm{m}^{3}$. Key compounds in the production of oxygen from lunar material by hydrogen reduction are the iron oxides and titanium dioxides.

The highest concentrations of iron oxide and titanium dioxide (and ilmenite, $\mathrm{FeTiO}_{3}$ ) occur in the low-lying mare regions. Within these mare regions of high iron and titanium content, ilmenite will be present in the loose regolith. About two thirds of the ilmenite is in glassy agglutinates and basaltic rock fragments much larger than the common regolith grain size. The average amount of small grain size ilmenite available in the mare regions is approximately 7 percent by weight (the ratio of mass of ilmenite to mass of regolith, $R_{m}$, is 0.07 ) and 5 percent by volume (the ratio of volume of ilmenite to volume of regolith, $R_{v}$, is 0.05 ) of the regolith (Ref. 4). Based on these percentages, the density of ilmenite $\left(\rho_{i}\right)$ is approximately 1.4 times that of the regolith or $1400 \mathrm{~kg} / \mathrm{m}^{3}$. The thermal conductivity of the fine-grained ilmenite is estimated to be $0.425 \mathrm{~W} / \mathrm{mK}$ which is similar to that of sand (Ref. 5).

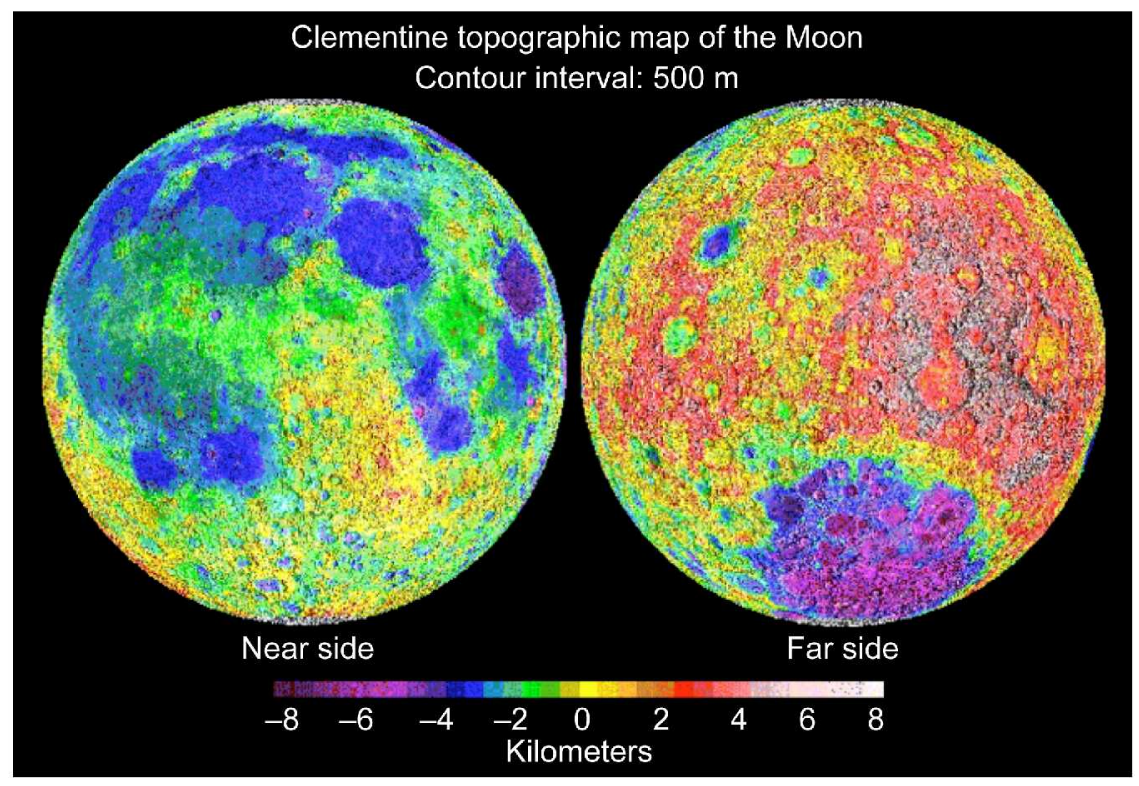

Figure 2.-Lunar topographic map from Reference 3.

TABLE 1.-LUNAR SURFACE MINERAL COMPOSITIONS (REFS. 1 AND 2)

\begin{tabular}{|l|c|c|}
\hline \multicolumn{1}{|c|}{ Compound } & $\begin{array}{c}\text { Highland, } \\
\text { wt\% }\end{array}$ & $\begin{array}{c}\text { Mare, } \\
\text { wt\% }\end{array}$ \\
\hline $\mathrm{SiO}_{2}$ & 44.5 & 41.0 \\
\hline $\mathrm{Al}_{2} \mathrm{O}_{3}$ & 26.0 & 12.8 \\
\hline $\mathrm{FeO}$ & 5.77 & 16.2 \\
\hline $\mathrm{CaO}$ & 14.9 & 12.4 \\
\hline $\mathrm{MgO}$ & 8.05 & 9.2 \\
\hline $\mathrm{TiO}_{2}$ & ---- & 7.3 \\
\hline
\end{tabular}




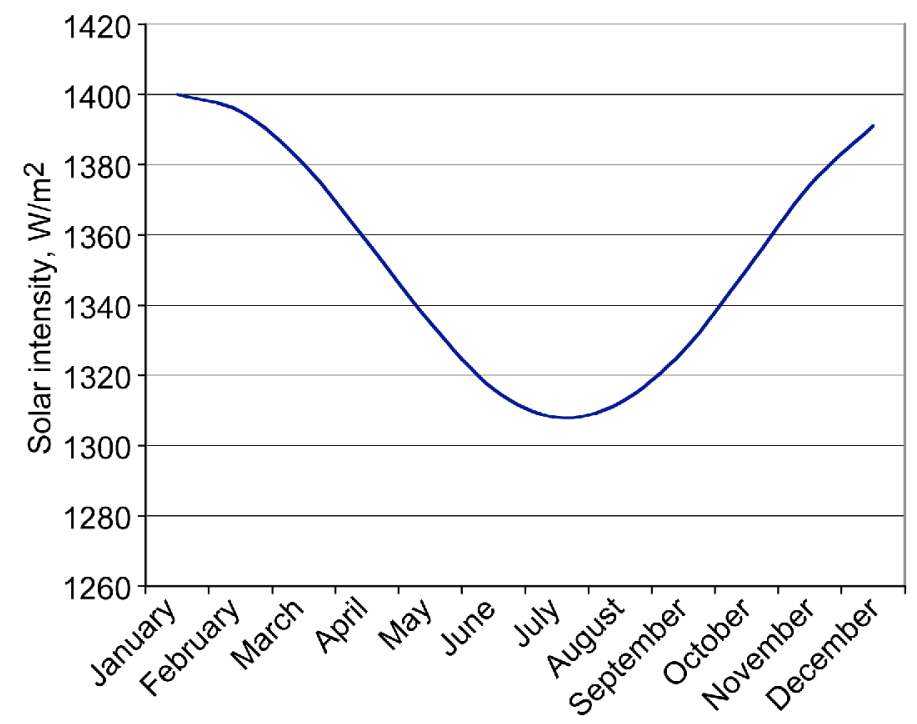

Figure 3.-Variation in solar intensity at Earth orbital location.

The specific heat of ilmenite is approximated by that of the mare regolith. The specific heat $\left(c_{p}\right)$ as a function of temperature ( $T$ ) is given by Equation (1) (Ref. 5).

$$
c_{p}=-1848.5+1047.41 \log \left(T_{i}\right) \quad[\mathrm{J} / \mathrm{kgK}]
$$

With the absence of an appreciable atmosphere, the solar intensity at the lunar surface is fairly constant. There is a slight variation throughout the year due to the Earth's orbital eccentricity about the Sun. The mean solar intensity $\left(I_{m}\right)$ at Earth's orbital location is $1353 \mathrm{~W} / \mathrm{m}^{2}$ (Ref. 6). The variation in Earth's orbital radius $\left(r_{\mathrm{orb}}\right)$ from the mean orbital radius $\left(r_{\text {orbm }}\right.$, which has a value of $\left.1.496 \mathrm{E} 8 \mathrm{~km}\right)$ is represented by the eccentricity $(\varepsilon)$ of Earth's orbit that has a value of 0.017 . The actual solar flux (or intensity, $I$ ) in $\mathrm{W} / \mathrm{m}^{2}$ for a specific day of the year is determined by Equations (2) and (3). This variation in solar intensity throughout the year is shown in Figure 3.

$$
\begin{gathered}
I=I_{m}\left(r_{\mathrm{orbm}}{ }^{2} / r_{\mathrm{orb}}{ }^{2}\right) \\
r_{\mathrm{orb}}=\left(1-\varepsilon^{2}\right) /(1+\varepsilon \operatorname{Cos}(\alpha))
\end{gathered}
$$

The day angle ( $\alpha$ ) used in Equation (3) is defined as $0^{\circ}$ on January 4th (perihelion of Earth's orbit) and increases by $0.98^{\circ}$ per day. The solar output varies from approximately $1400 \mathrm{~W} / \mathrm{m}^{2}$ (on January 4 th) to $1308 \mathrm{~W} / \mathrm{m}^{2}$ (on July 9th). The variation of the solar intensity at the lunar surface due to the orbit of the Moon around the Earth is very slight. The distance between the Moon and Earth varies between $360,300 \mathrm{~km}$ (at perigee) to 405,500 (at apogee). The greatest effect on solar intensity produced by the Moon's orbit about the Earth is a decrease of about 0.56 percent $\left(-6 \mathrm{~W} / \mathrm{m}^{2}\right)$ in the solar intensity at the Lunar surface. This small change in intensity will vary as the Moon orbits the Earth or in other words throughout the lunar day. Therefore it was assumed to be negligible and the solar intensity at Earth orbit was utilized in the subsequent analysis.

\section{Oxygen Production by Hydrogen Reduction of Ilmenite-Process Overview}

There are a number of potential methods for extracting oxygen from the lunar soil (Ref. 2). The method examined in this section of our analytical study is the hydrogen reduction of ilmenite. This is one of the methods of oxygen production from Lunar regolith that is under active development. It is a fairly simple method that can be accomplished with present day materials. Because the reaction takes place at a relatively low temperature, below the melting point of the soil, the material compatibility and corrosiveness are not significant issues. The process utilizes hydrogen gas that will need to be supplied from Earth. However, the gas is recoverable in the oxygen generation process. Therefore after the initial supply only make-up gas will be needed to account for that which is not recovered or lost through leaking. Another advantage of this type of production is that it can utilize the surface regolith in areas that have a high iron and titanium content. This eliminates the need for the mining or processing of 
rocks, these are both very power intensive. For an initial oxygen production capability, and as a means of demonstrating the oxygen production technology, being able to directly utilize regolith is a significant advantage.

Hydrogen reduction of ilmenite is a two-step process represented by the reactions given in

Equations (4) and (5) (Refs. 2 and 4). The first step in the process is the reduction of the ilmenite to iron, titanium dioxide, and water. The second step is the electrolysis of the water to form hydrogen and oxygen.

$$
\begin{aligned}
2 \mathrm{FeTiO}_{3}+2 \mathrm{H}_{2} & \rightarrow 2 \mathrm{Fe}+2 \mathrm{TiO}_{2}+2 \mathrm{H}_{2} \mathrm{O} \\
2 \mathrm{H}_{2} \mathrm{O} & \rightarrow 2 \mathrm{H}_{2}+\mathrm{O}_{2}
\end{aligned}
$$

Both the hydrogen and oxygen that are produced in the process can be captured. The oxygen will be stored for use and the hydrogen will be reused in the process. The reduction process is performed in a fluidized bed reactor and the electrolysis is performed with an electrolyzer. A diagram of the process is given in Figure 4.

The process requires the ilmenite to remain at an elevated temperature $\left(T_{i}\right)$ of $1273 \mathrm{~K}$ for approximately $1 \mathrm{hr}$. An additional benefit to the heating of the ilmenite is the liberation of hydrogen. Hydrogen is present in mature lunar regolith due to exposure to the solar wind over long periods of time. The finer the particle grains the larger the amount of hydrogen it will have trapped. Hydrogen content will range from 0.1 to $0.2 \mathrm{~kg} / \mathrm{m}^{3}$ of regolith. Since hydrogen content is dependent on grain size not material content it is reasonable to assume the concentration in the ilmenite is the same as that in the overall regolith. Therefore, as the ilmenite is heated the hydrogen bonded to it will be released. It is estimated that at $900^{\circ} \mathrm{C}$ all of the hydrogen trapped with the ilmenite will be released. Released hydrogen will be utilized in the reduction of the ilmenite and will add to the overall hydrogen already in the system. It can be considered a source of makeup hydrogen to help offset any losses of hydrogen from the system. The sequence for the process illustrated in Figure 4 consists of the following:

- Scooping the regolith and transporting it to the screen.

- The larger regolith particles (greater than $1 \mathrm{~mm}$ in diameter) are separated using a vibrating screen.

- The regolith is then transported to a magnetic separator where the ilmenite is separated from the regolith.

- The ilmenite is transported to the fluidized bed reactor.

- In the reactor the ilmenite is heated while hydrogen gas is circulated (it is maintained at $1273 \mathrm{~K} \mathrm{for} 1 \mathrm{hr}$ ).

- The water vapor output is passed through an electrolyzer where it is separated into hydrogen and oxygen gas.

- The hydrogen gas is returned to the reactor and the oxygen is stored.

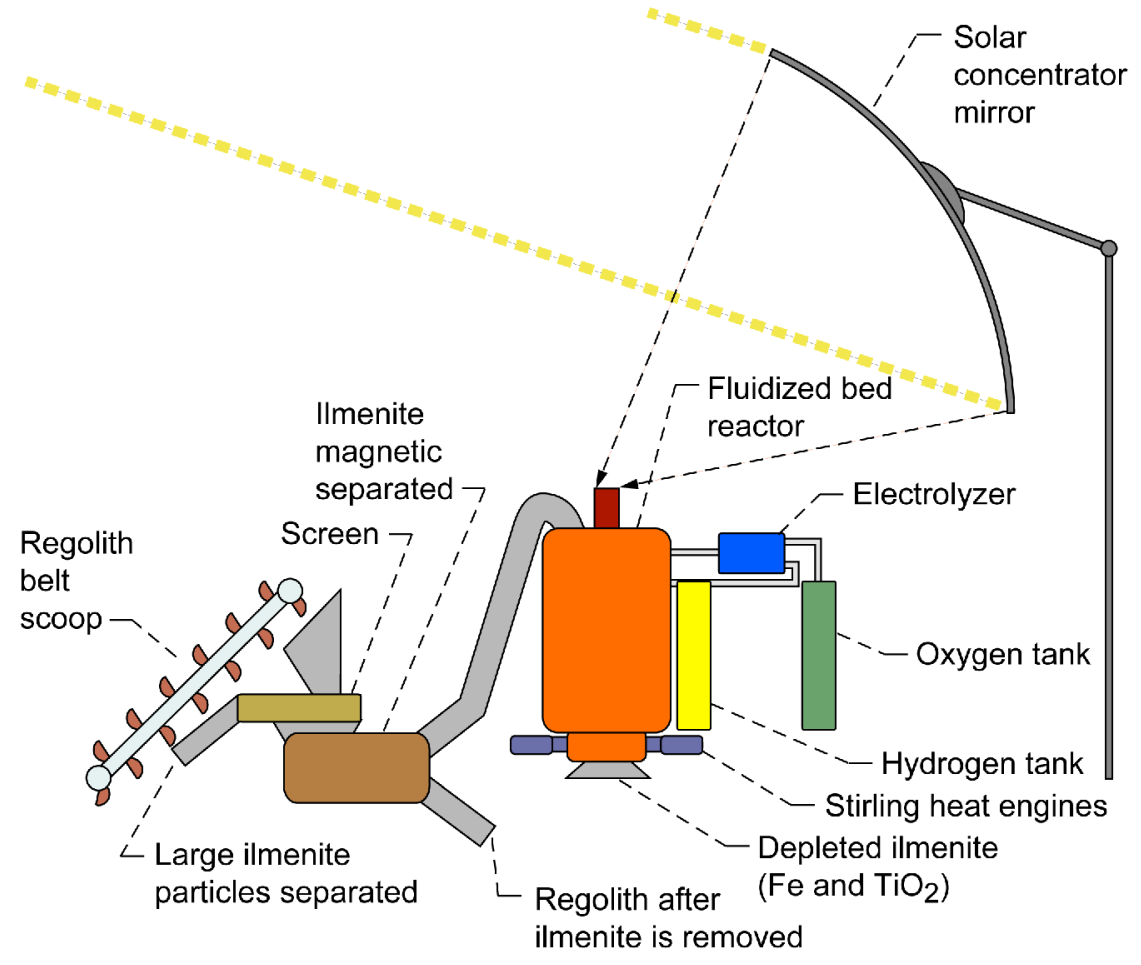

Figure 4.-Diagram of hydrogen reduction of ilmenite oxygen production processing system. 


\section{Methodology for Sizing of Integrated Power System for Hydrogen Reduction}

An analysis was set up to evaluate the sizing of the system shown in Figure 4 for various rates of oxygen production (Ref. 7).

The sizing was based on scaling the solar dynamic system to provide sufficient heat to run the ilmenite reduction reaction as well as provide electrical power for operating all of the other process involved with the oxygen production. The electrical power is produced by a series of Stirling heat engines. To perform the sizing analysis an energy balance between the heat provided by the concentrator mirror and the requirements of the various components both thermally and electrically had to be made. Each of the components' thermal or electrical energy consumption has to be determined and scaled with the amount of regolith and or ilmenite being processed. Since the process involves moving the material around, the height and rate of movement is needed in order to determine the energy consumption. These values can be varied to determine what effect they have on the system sizing and production rate.

The rate of ilmenite going into the reactor sets the rates for all of the other processes. This rate can be represented by the fraction of the reactor volume that is replenished each hour, $\dot{V}_{i r}$. This quantity will have a value between 0 and 1. Establishing the replacement rate of the ilmenite in the reactor also sets the volume and mass flow requirements for all the other process in the system. From this, the mass rate at which the regolith must be acquired from the surface ( $\dot{M}_{r}$ in kilograms per hour) can be determined. This rate, which is based on the total volume of ilmenite in the fluidized bed reactor, is given by Equation (6). The reactor is assumed to be cylindrical. The diameter $\left(d_{r}\right)$ and height $\left(h_{r},\right)$ can be adjusted to increase or decrease the overall volume of ilmenite processed.

$$
\dot{M}_{r}=\frac{\rho_{i} \dot{V}_{i r} \pi d_{r}^{2} h_{r}}{4 R_{m}}
$$

The rate at which the regolith is taken from the surface sets the power required to scoop the regolith $\left(P_{r s}\right)$ and transport it to the screen $\left(P_{r l}\right)$. These quantities are given in Equations (7) and (8), respectively. The power to scoop the regolith is dependent on the distance the belt scoops travel in the regolith $\left(d_{r s}\right.$, assumed to be $\left.1 \mathrm{~m}\right)$ and the coefficient of friction of the regolith $\left(\mu_{r}\right)$. The regolith coefficient of friction was assumed to be 0.4 , which is similar to that of sand. The power to lift the regolith is dependent on the height it is raised. This height is assumed to be the height of the reactor plus the height the reactor is above the surface $\left(h_{r s}\right.$, assumed to be $\left.1 \mathrm{~m}\right)$. The electric motor efficiency $\left(\eta_{e m}\right)$ to drive the scoop and lift the regolith is assumed to be 90 percent.

$$
\begin{gathered}
P_{r s}=\frac{\mu_{r} d_{r s} \dot{M}_{r} g}{3600 \eta_{e m}} \\
P_{r l}=\frac{\left(h_{r}+h_{r s}\right) \dot{M}_{r} g}{3600 \eta_{e m}}
\end{gathered}
$$

Once the regolith is picked up off of the surface, the first step is to screen out the larger particles; those greater then a specific size are removed. This screening is necessary for the efficient operation of the fluidized bed reactor. The maximum particle size $\left(d_{s}\right)$ and subsequent screen opening that allows for efficient fluidization is calculated in Equation (9) (Ref. 4). This equation has to be solved iteratively for the maximum particle size. It factors in a number of parameters for the operation of the fluidized bed reactor. These include the porosity of the fluidized bed $\left(\varepsilon_{p}\right.$, estimated to be 0.5$)$ and the hydrogen gas velocity within the reactor $\left(U_{\mathrm{H} 2}\right.$, estimated to be $\left.0.3 \mathrm{~m} / \mathrm{s}\right)$. Details on the hydrogen gas properties and the ilmenite are also required. These include the hydrogen gas density $\left(\rho_{\mathrm{H} 2}\right.$, given in Equation (10)), hydrogen viscosity ( $\mu_{\mathrm{H} 2}$, estimated to be $\left.2.37 \mathrm{E}-5 \mathrm{~kg} / \mathrm{m}-\mathrm{s}\right)$, (Ref. 4) ilmenite particle shape factor $(\phi$, estimated to be that of sand, 0.83 ) and the ilmenite particle density $\left(\rho_{i p}\right.$, estimated to be $\left.4790 \mathrm{~kg} / \mathrm{m}^{3}\right)$. The ilmenite particle density is greater than that of the ilmenite in the soil. This is because the density of the ilmenite in the soil takes into account any spacing between the particles where as the particle density is that of the material that makes up each particle. 


$$
\frac{150 \rho_{H 2}\left(1-\varepsilon_{p}\right) U_{H 2}}{\varphi^{2} \varepsilon_{p}^{3} \mu_{H 2}}=\frac{g \rho_{H 2}\left(\rho_{i p}-\rho_{H 2}\right)}{\mu_{H 2}^{2}} d_{i}^{2}-\frac{1.75 \rho_{H 2}^{2} U_{H 2}^{2}}{\varphi \varepsilon_{p}^{3} \mu_{H 2}^{2}} d_{i}
$$

The hydrogen gas density is based on the ideal gas law (pressure $\left(P_{\mathrm{H} 2}\right)$ in Pascal, temperature $\left(T_{i}\right)$ in degrees Kelvin and the gas constant for hydrogen $\left.\left(R_{\mathrm{H} 2}\right), 4157 \mathrm{Nm} / \mathrm{kgK}\right)$ with a compressibility factor $\left(Z_{\mathrm{H} 2}\right)$ for the hydrogen gas (Ref. 8).

$$
\begin{gathered}
\rho_{\mathrm{H} 2}=\frac{P_{\mathrm{H} 2}}{Z_{\mathrm{H} 2} R_{\mathrm{H} 2} T_{i}} \\
Z_{\mathrm{H} 2}=0.99704+6.4149 E-9 P_{\mathrm{H} 2}
\end{gathered}
$$

The screening method selected for this analysis is a vibratory screen. A vibratory screening process is fairly simple. A screen with a specified mesh or opening size is vibrated as the regolith is poured onto it. The material that is less than the opening size will fall through to the next stage in the process whereas the material larger than the openings will be moved across the screen surface and discharged off one end of the screen and returned to the lunar surface. The power required to operate the vibratory screener $\left(P_{v s}\right)$ is given by Equation (12) (Ref. 4).

$$
P_{v s}=\frac{0.45 \dot{M}_{r}}{507.72 d_{i}+49.91 \sqrt{d_{i}}}
$$

The screening process will eliminate a portion of the regolith that was collected. The fraction of the regolith that will make it through the screen will depend on the desired maximum particle size determined by Equation (9). The particle size distribution $\left(n_{r}\right)$ of the regolith in meters is given by Equation (13). This equation is a curve fit representation of data on the percent concentration of particle size within the regolith (Ref. 4). The particle size distribution along with the corresponding curve fit is plotted in Figure 5.

$$
n_{r}=\frac{d_{i}-9.4008 E-6}{d_{i}+8.0419 E-5}
$$

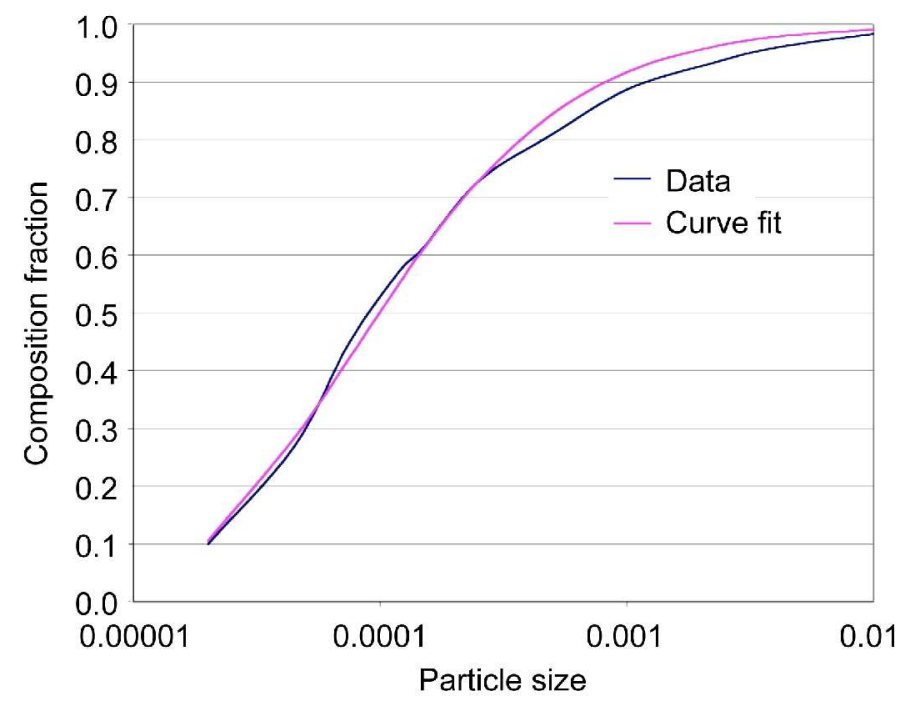

Figure 5.-Particle size distribution of Lunar regolith. 
The next step in the process is to separate out the ilmenite from the regolith. For a smaller scale oxygen production plant the use of a permanent or electro-magnet separator is preferred. This type of separator minimizes the power requirements compared to an induced magnetic roll separator or an electrostatic separator. This type of separator consists of a drum with alternating magnetic poles along its surface. Material is dropped over the drum as it rotates. Magnetic material will adhere to the surface where it is scrapped off and captured. Nonmagnetic material will drop out of the bottom of the separator (Ref. 9). Power consumed by the separator $\left(P_{m s}\right)$ in Watts is given by Equation (14) (Ref. 4).

$$
P_{m s}=0.196 n_{r} \dot{M}_{r}
$$

The separated ilmenite has to now be lifted into the fluidized bed reactor. This distance is assumed to be the height of the reactor plus the distance the reactor is above the surface. The power required to lift the ilmenite $\left(P_{i l}\right)$ is given by Equation (15). Where the mass flow of ilmenite in kilograms per hour is given by Equation (16). It is assumed that the separation process is 90 percent efficient $\left(\eta_{s}\right)$. Therefore 90 percent of the mass flow given by Equation (15) will be ilmenite. The remainder will be other materials that will not contribute to the reaction although it will go through the complete heating process.

$$
\begin{gathered}
P_{i l}=\frac{\left(h_{r}+h_{r s}\right) \dot{M}_{i} g}{3600 \eta_{e m}} \\
\dot{M}_{i}=n_{r} R_{m} \dot{M}_{r}
\end{gathered}
$$

Once the ilmenite enters the fluidized bed reactor it is heated to $1273 \mathrm{~K}$ and hydrogen gas is circulated through it. The energy to heat the soil comes from the solar concentrator. The concentrated solar radiation is focused onto a heat receiver. This heat receiver then conducts the heat into the reactor chamber where it is distributed throughout the chamber to heat the ilmenite. It is assumed that the ilmenite will heat uniformly once it is placed in the reactor. As the ilmenite passes from the top of the reactor to the bottom it is slowly heated. The selected rate, at which the volume of ilmenite in the reactor is replaced, given previously as $\dot{V}_{i}$, sets the amount of heat needed to heat the soil. The ilmenite must be brought up to temperature and remain at temperature for a specified period of time $\left(t_{t}\right.$, in hours) in order for the reduction reaction (given by Eq. (4)) to take place. The time available to heat the ilmenite ( $t_{h}$, in hours) is given by Equation (17). From this equation it should be observed that there is an inherent limit on the rate at which the ilmenite is replaced and the duration at which it must be at temperature. This is because the time available to heat the ilmenite must be greater than zero.

$$
t_{h}=\left(\frac{1}{\dot{V}_{i r}}-t_{t}\right) \text { where } \dot{V}_{i r} t_{t}<1
$$

The thermal power required to heat the ilmenite $\left(Q_{h i}\right)$, given by Equation (18), is dependent on this available heating time, the volume of ilmenite being heated and the initial ilmenite properties. It is assumed that the ilmenite is initially at the illuminated surface temperature $\left(T_{i o}\right)$ of $384 \mathrm{~K}$.

$$
Q_{h i}=\frac{\rho_{i} c_{p}\left(T_{i}-T_{i o}\right) \pi d_{r}^{2} h_{r}\left(1-t_{t} \dot{V}_{i r}\right)}{14,400 t_{h}}
$$

The ilmenite will lose heat to the surroundings $\left(Q_{l s}\right)$ as it is being heated. To minimize this heat loss, the outside of the reactor vessel can be insulated with multilayer insulation. Because of the vacuum conditions at the lunar surface, radiation heat transfer is the only mechanism in which the reactor vessel will transfer heat to the surroundings. Therefore multiple layers of a low emissivity $\left(\varepsilon_{l}\right)$ material (such as polished nickel, $\varepsilon_{l}=0.17$ ) that are closely layered will provide very good insulation. The greater the number of layers $\left(n_{l}\right)$ and the smaller the spacing between the layers $\left(d_{i l}\right)$, the less the heat loss to the surroundings will be. The heat loss to the surroundings (at a sink temperature $T_{s}=270 \mathrm{~K}$ ) from the insulated reactor vessel can be calculated from Equation (19) where the StefanBoltzman constant $(\sigma)$ has a value of $5.67 \mathrm{E}-8 \mathrm{~W} / \mathrm{m}^{2} \mathrm{~K}$. If the reactor is constructed of a material different than that of the insulation it will have a different emissivity $\left(\varepsilon_{r}\right.$. such as chromium $\left.\varepsilon_{r}=0.14\right)$. 


$$
Q_{l s}=\frac{\pi\left(d_{r}+n_{l} d_{i l}\right) h_{r} \sigma\left(T_{i}^{4}-T_{s}^{4}\right)}{\left(\frac{1}{\varepsilon_{c}}+\frac{2 n_{l}}{\varepsilon_{i}}-n_{l}+1\right)}
$$

In addition to the heat required to bring the ilmenite to the desired temperature and the loss of heat to the surroundings, the hydrogen reduction reaction itself will absorb heat from the system. The amount of heat consumed $\left(Q_{r}\right)$ due to the heat of reaction $\left(H_{r}\right)$ is given by Equation (20). The heat of reaction for the hydrogen reduction of ilmenite is given as $294,000 \mathrm{~J} / \mathrm{kg}$ (Ref. 4).

$$
Q_{r}=\frac{H_{r} \eta_{s} \dot{M}_{i}}{3600}
$$

The last power-consuming component of the system is the electrolyzer. The electrolyzer power requirement will depend on the amount of water that needs to be electrolyzed. The rate of water production $\left(\dot{M}_{w}\right)$ is based on the ratio of the molecular weights of the reactant and product of interest, water. The rate of water production in kilograms per hour is given by Equation (21). Subsequently the rate of oxygen production $\left(\dot{M}_{o}\right)$ can then be determined, which is given by Equation (22).

$$
\begin{gathered}
\dot{M}_{w}=\eta_{s} \dot{M}_{i} \frac{18}{308} \\
\dot{M}_{o}=\dot{M}_{w} \frac{16}{18}
\end{gathered}
$$

The power required by the electrolyzer to separate the water into hydrogen and oxygen can be calculated based on the theoretical power needed to break apart water $(3520 \mathrm{~W} / \mathrm{kg} / \mathrm{hr})$, the efficiency of the electrolyzer $\left(\eta_{e}\right)$ and the rate of water flow to the electrolyzer, see Equation (23).

$$
P_{e}=3520 \frac{\dot{M}_{w}}{\eta_{e}}
$$

The electrical power to operate the scoop and belt motors, run the magnetic separator and vibratory separator and operate the electrolyzer is provided by a number of Stirling heat engines. The required power output $\left(P_{s e}\right)$ of these engines is given by Equation (24) and the subsequent heat input to the system to run the engines is given by Equation (25). This heat input is based on the conversion efficiency of the Stirling engine $\left(\eta_{s e}\right)$ that is estimated to be 35 percent.

$$
\begin{gathered}
P_{s e}=P_{r s}+P_{r l}+P_{v s}+P_{m s}+P_{i l}+P_{e} \\
Q_{s e}=\frac{P_{s e}}{\eta_{s e}}
\end{gathered}
$$

The total thermal power output needed and the corresponding diameter of the solar concentrator mirror $\left(d_{m}\right)$ can now be calculated. The total thermal power $\left(Q_{\text {total }}\right)$ output is given by Equation (26). The required solar concentrator diameter is given by Equation (27) and assumes it is circular in shape. The diameter is dependent on the mirror reflectance efficiency $\left(\eta_{m}\right)$ and the efficiency of the heat receiver $\left(\eta_{r}\right)$.

$$
\begin{gathered}
Q_{\text {total }}=Q_{s e}+Q_{r}+Q_{l s}+Q_{h i} \\
d_{m}=\sqrt{\frac{4 Q_{\mathrm{total}}}{\pi \eta_{m} \eta_{r} I}}
\end{gathered}
$$




\section{Results of Sizing of Integrated Power System for Hydrogen Reduction}

Utilizing the analysis outlined in the previous section, data was produced on the achievable oxygen production rate for various size systems. Initially a baseline case was produced that represents the initial design and operation point for the system. The baseline assumptions that were used to generate this case are given in Table 2 . These assumptions represent the best estimates of the performance for the various components as well as an initial sizing that is within the scope of a demonstration oxygen production system. The system sizing and performance results for the baseline system are given in Table 3; a breakdown of the thermal and electrical power requirements is shown in Figure 6.

TABLE 2.-BASELINE ANALYSIS ASSUMPTIONS

\begin{tabular}{|l|c|}
\hline \multicolumn{1}{|c|}{ Variable } & Value \\
\hline Fraction of the fluidized bed reactor that is replenished each hour $\left(\dot{V}_{i r}\right)$ & $0.1(1 / \mathrm{hr})$ \\
\hline Reactor diameter $\left(d_{r}\right)$ & $0.5 \mathrm{~m}$ \\
\hline Reactor height $\left(h_{r}\right)$ & $0.5 \mathrm{~m}$ \\
\hline Operational date, day angle $(\alpha)$ & July 9 th, $180^{\circ}$ \\
\hline Distance the scoop is in the Regolith $\left(d_{r s}\right)$ & $1 \mathrm{~m}$ \\
\hline Height the fluidized bed reactor is above the surface $\left(h_{r s}\right)$ & $1 \mathrm{~m}$ \\
\hline Porosity of the fluidized bed $\left(\varepsilon_{p}\right)$ & 0.5 \\
\hline Hydrogen velocity through the fluidized bed $\left(U_{\mathrm{H} 2}\right)$ & $0.3 \mathrm{~m} / \mathrm{s}$ \\
\hline Hydrogen pressure within the fluidized bed $\left(P_{\mathrm{H} 2}\right)$ & $1 \mathrm{E} 6 \mathrm{~Pa}(10 \mathrm{~atm})$ \\
\hline Ilmenite hydrogen reduction reaction temperature $\left(T_{i}\right)$ & $1273 \mathrm{~K}$ \\
\hline Time ilmenite is held at reaction temperature $\left(t_{t}\right)$ & $1 \mathrm{hr}$ \\
\hline Number of layers of MLI insulation $\left(n_{l}\right)$ & 50 \\
\hline Sink temperature of surroundings $\left(T_{s}\right)$ & $270 \mathrm{~K}$ \\
\hline Electric motor efficiency $\left(\eta_{e m}\right)$ & 0.90 \\
\hline Ilmenite separation efficiency $\left(\eta_{s}\right)$ & 0.90 \\
\hline Electrolyzer efficiency & 0.72 \\
\hline Stirling engine efficiency & 0.35 \\
\hline Concentrator mirror efficiency & 0.90 \\
\hline Heat receiver efficiency & 0.90 \\
\hline
\end{tabular}

TABLE 3.-BASELINE SIZING AND PERFORMANCE RESULTS

\begin{tabular}{|l|c|}
\hline \multicolumn{1}{|c|}{ Quantity } & Value \\
\hline Available solar intensity & $1301 \mathrm{~W} / \mathrm{m}^{2}$ \\
\hline Total thermal power required & $15,241 \mathrm{~W}$ \\
\hline Total electrical power required & $3,272 \mathrm{~W}$ \\
\hline Concentrator mirror area/diameter & $14.38 \mathrm{~m}^{2} / 4.28 \mathrm{~m}$ \\
\hline Reactor volume & $0.098 \mathrm{~m}^{3}$ \\
\hline Maximum particle size & $0.842 \mathrm{~mm}$ \\
\hline Total mass of hydrogen required & $0.73 \mathrm{~kg}$ \\
\hline Water production rate & $0.653 \mathrm{~kg} / \mathrm{hr}$ \\
\hline Oxygen production rate & $0.58 \mathrm{~kg} / \mathrm{hr}$ \\
\hline
\end{tabular}




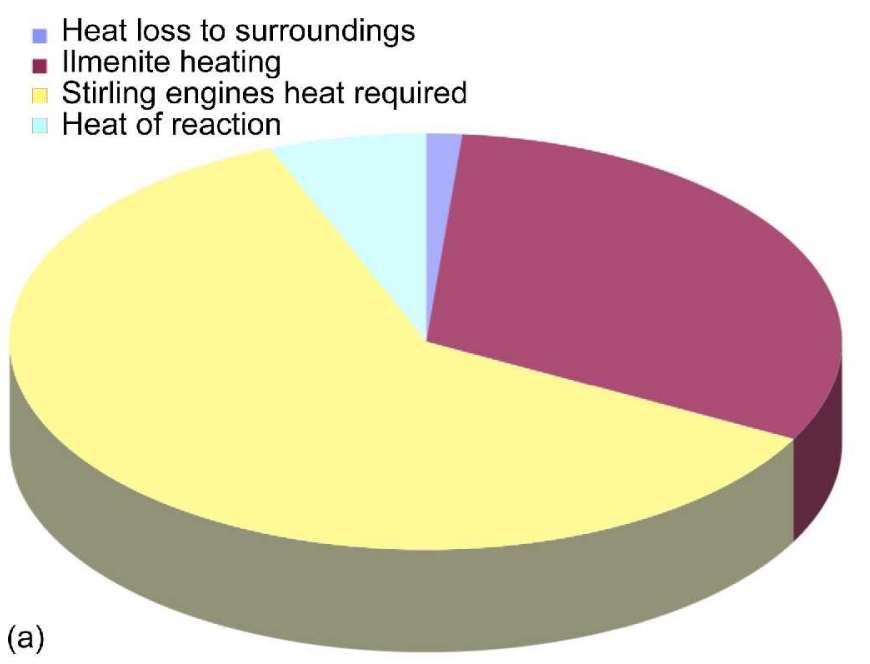

Operate electrolyzer
Process Regolith
(lift, scoop, vibrate, separate)

(b)

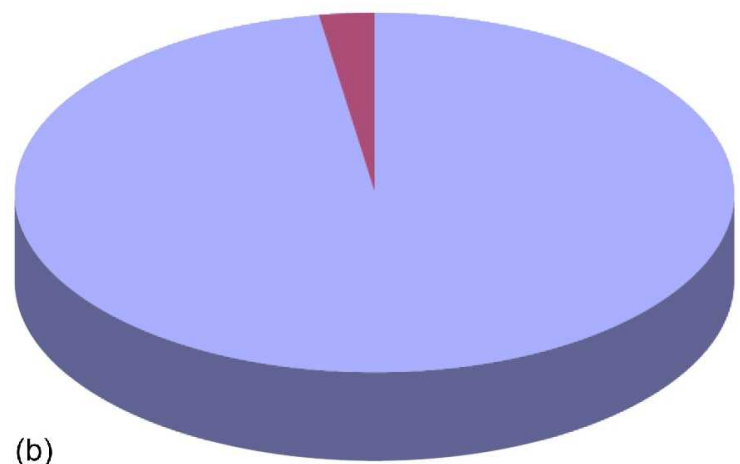

Figure 6.-Breakdown of thermal power (a) and electrical power (b) requirements.

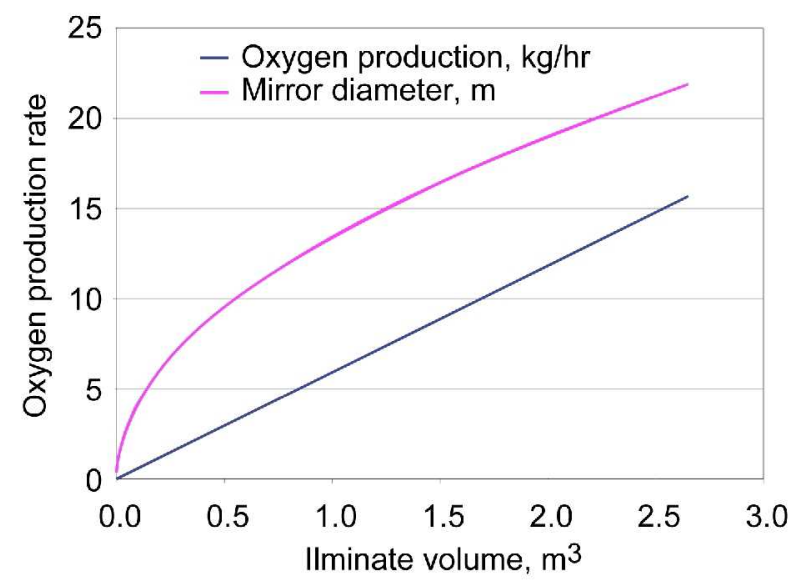

Figure 7.-Oxygen production rate and mirror diameter for various volume reactors.

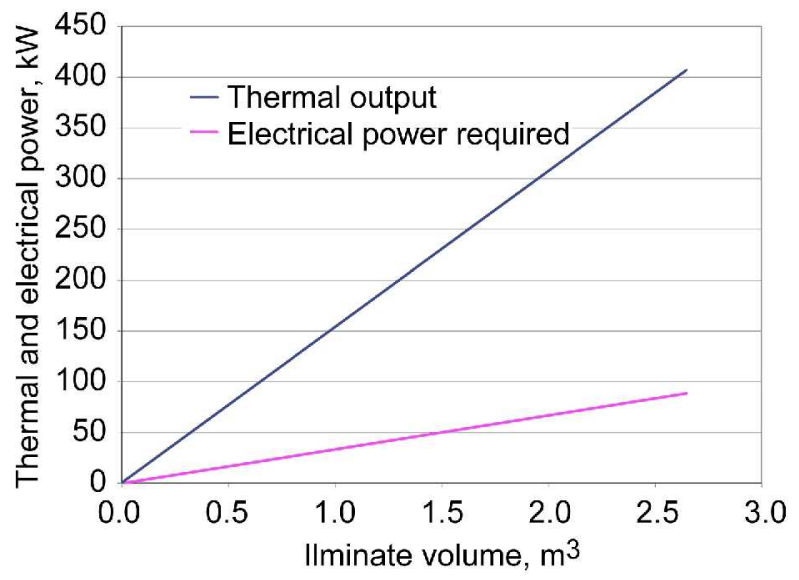

Figure 8.-Thermal and electrical output requirements for various volume reactors.

From this initial case, variations were made to some of the variables to determine what impact they have on the system sizing and output. The container volume was varied from near zero to $2.5 \mathrm{~m}^{3}$. The remaining variables, given in Table 2, were not changed. The corresponding oxygen production rate and mirror diameter are plotted in Figure 7 and the required thermal and electrical output is plotted in Figure 8. From these figures it can be seen that there is a linear increase in oxygen production with the increase in reactor volume. This should be expected since the amount of oxygen is directly proportional to the volume of ilmenite being reduced. The thermal and electrical power requirements also increase linearly with the reactor volume.

Another means of changing the rate of oxygen production is to vary the rate at which the ilmenite is replaced in the reactor. For the baseline case this rate was set at 10 percent of the container volume per hour. By varying this rate the amount of oxygen produced will change as well as the required thermal power and correspondingly mirror size. The oxygen production rate and the required mirror diameter as a function of the fraction of the ilmenite in the reactor replaced each hour is shown in Figure 9. Figure 10 shows the thermal and electrical power required as a function of the fraction of ilmenite replaced in the reactor each hour.

Using the data produced a direct comparison between the oxygen production rate and the mirror diameter can be made. This comparison is plotted in Figure 11 for both the variable volume and the variable rate cases. From this figure it can be seen that for a given oxygen production rate the required mirror diameter is basically the same between the variable volume or rate cases. Therefore higher production rates can be achieved either through increasing the volume of the reactor or by increasing the rate at which the ilmenite is processed through the reactor. In either case, for a given rate of oxygen production the effect on the thermal and power system sizing is the same. 


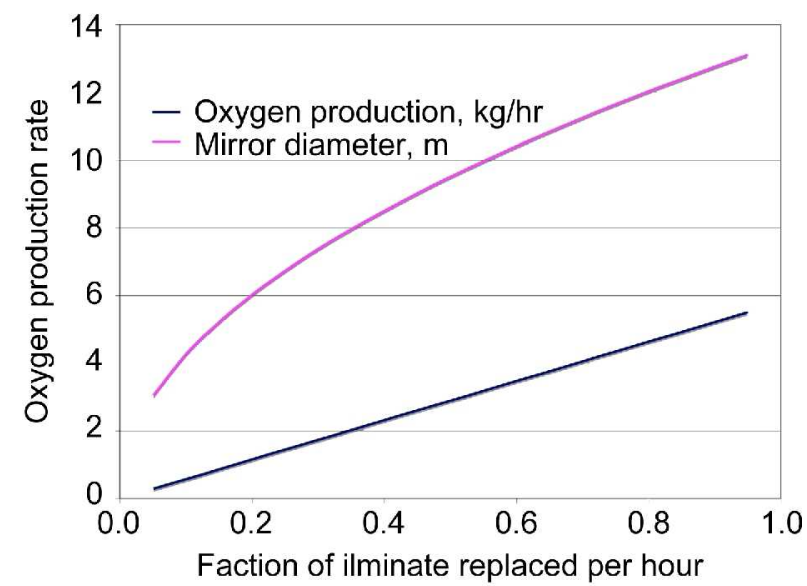

Figure 9.-Oxygen production rate and mirror diameter for different rates of ilmenite replacement.

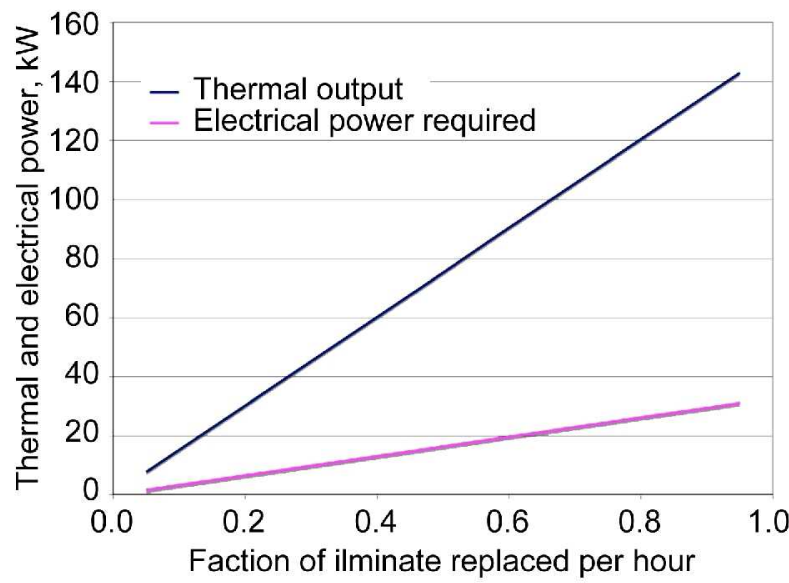

Figure 10.-Thermal and electrical output requirements for different rates of ilmenite replacement.

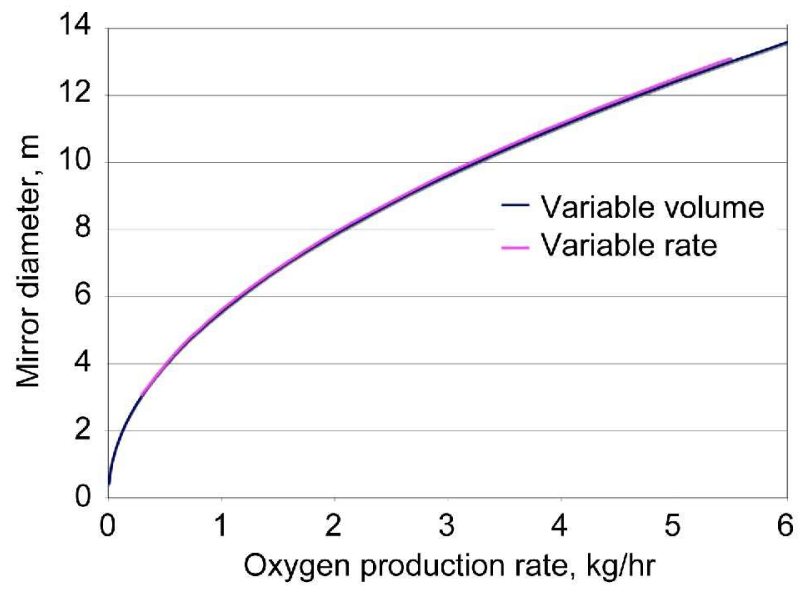

Figure 11.-Mirror size as a function of oxygen production rate for both variable volume and rate.

\section{Oxygen Production by Carbothermal Processing}

The Carbothermal Reduction process utilizes carbon to bond with the oxygen contained in the oxides within the regolith. Each of the compounds in Table 1 (materials less than 1 percent were excluded) reacts under high temperatures $\left(190{ }^{\circ} \mathrm{C}\right.$ ) in the presence of a carbon rich environment (in this case, methane, $\left.\mathrm{CH}_{4}\right)(\mathrm{Ref} .10)$. Methane is introduced to the metal oxides at the elevated temperature, and extracts oxygen (using the carbon) to leave behind the metal (Eq. (28)). The $\mathrm{CO}$ and $\mathrm{H}_{2}$ are then transferred to a methanation reactor where additional $\mathrm{H}_{2}$ is added. These gases react to form $\mathrm{CH}_{4}$ (which would be reused in the first reaction) and $\mathrm{H}_{2} \mathrm{O}$ (Eq. (29)). The last step would involve electrolyzing the $\mathrm{H}_{2} \mathrm{O}$ to form $\mathrm{H}_{2}$ (which would be reused in the methanation reaction) and $\mathrm{O}_{2}$ (which would be stored) (Eq. (30)).

$$
\begin{gathered}
\mathrm{MO}_{\mathrm{x}}+x \mathrm{CH}_{4} \rightarrow \mathrm{M}+x \mathrm{CO}+2 x \mathrm{H}_{2} \\
x \mathrm{CO}_{\mathrm{x}}+3 x \mathrm{H}_{2} \rightarrow x \mathrm{CH}_{4}+x \mathrm{H}_{2} \mathrm{O} \\
x \mathrm{H}_{2} \mathrm{O} \rightarrow x \mathrm{H}_{2}+0.5 x \mathrm{O}_{2}
\end{gathered}
$$




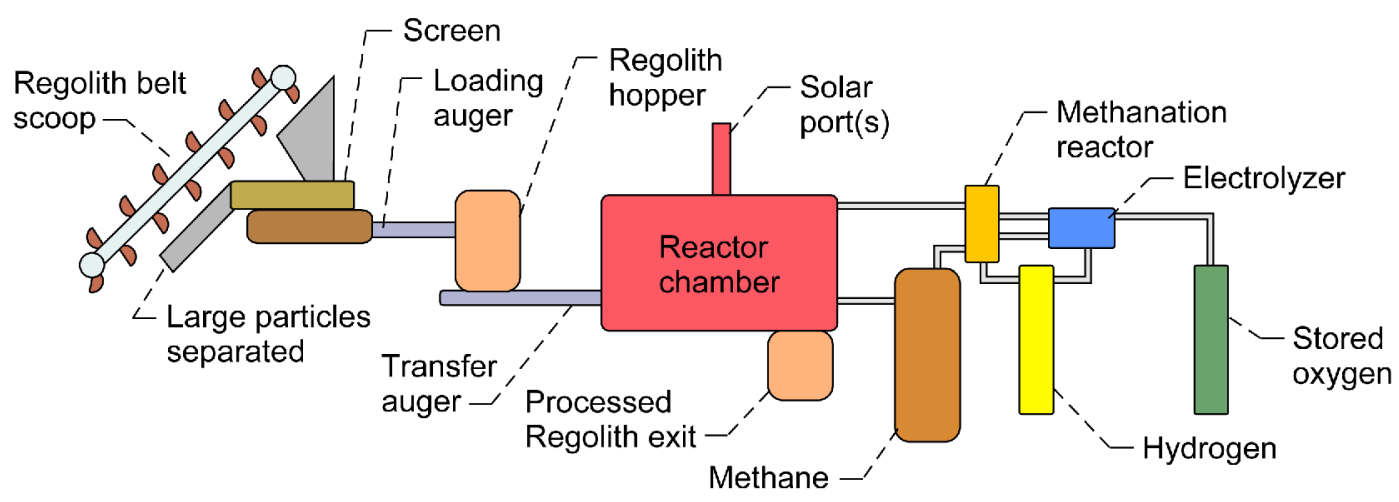

Figure 12.-Diagram of the carbothermal reduction process with identified features.

Orbital Technologies Corporation (ORBITEC) has developed a module to extract oxygen using the Carbothermal Reduction method discussed above. The modeled system is shown in Figure 12. The steps in the process are as follows:

- Scoop the regolith from the surface and transport it to the module.

- Separate the large particles from the regolith using a vibrating screen.

- Transport the regolith to the regolith hopper then to the reactor chamber using two augers.

- Heat the regolith to $1900^{\circ} \mathrm{C}$ by using concentrated solar energy, and circulate methane.

- Extract the processed regolith and transport the produced carbon monoxide and hydrogen gas to the methanation reactor.

- Mix additional hydrogen with the products in the methanation reactor to produce water and methane.

- Methane is returned to the system.

- Electrolyze the water to produce hydrogen and oxygen.

- The hydrogen is returned to the system and the oxygen is stored.

The first step in the process is to gather and transport the regolith to the module. This analysis considers a belt scoop to accomplish both tasks. The regolith would then be screened to remove large particles. This would ensure that the system did not jam. The next step involved transporting the regolith to the reactor chamber, which was done by two augers. Once in the reactor chamber, concentrated solar energy would be used to melt the regolith. The chamber could process 7 melts simultaneously. After the melt(s) reach the required temperature, methane gas would be introduced and the first reaction would take place (Eq. (28)). The processed regolith could then be scooped out using a rake, while the reactant gasses $\left(\mathrm{CO}\right.$ and $\left.\mathrm{H}_{2}\right)$ would enter into the methanation reactor (Eq. (29)). Water would then be extracted and cleaned of any impurities. Finally, oxygen is extracted from the water by an electrolyzer.

To determine the total power requirement of the entire system, the power requirement of each individual component was either calculated or estimated. Since it was known that the desired oxygen production is $1000 \mathrm{~kg} /$ year and that the typical oxygen yield is 15 to $20 \mathrm{wt} \%$, the minimum mass flow rate of the regolith can be determined (Ref. 10). It was assumed that the lunar location could be at any site, so therefore the carbothermal module would only be operational approximately half of the year $(4380 \mathrm{hr})$. The mass flow rate of the regolith $\left(\dot{M}_{r}\right.$ ) can be determined from Equation (31):

$$
\dot{M}_{r}=\frac{m_{O}}{t_{s}\left(y_{O}\right)}
$$

Where $m_{O}$ is the desired oxygen production per year $(\mathrm{kg}), t_{S}$ is the total amount of time of available sunlight (hours), and $y_{o}$ is the oxygen yield from the regolith. The mass flow rate of the regolith was used to determine the amount of power required at each stage. The first stage where power is needed is to scoop and lift the regolith. To do this, a belt scoop is utilized. The power of the scoop came from lifting the soil as well as the drag resistance against the regolith. It is assumed that the scoop is in contact with the reqolith for $1 \mathrm{~m}$. The distance to lift the regolith was determined by the height of the carbothermal module plus its distance above the surface. The electric motor 
efficiency was assumed to be 90 percent. The power requirement for scooping the regolith $\left(\mathbf{P}_{r s}\right)$ and lifting the regolith $\left(\mathbf{P}_{r l}\right)$ can be determined by Equations $(7)$ and $(8)$.

Several of the terms are identical to the hydrogen reduction case: $\eta_{e m}$ is the electrical efficiency of the motor, $\mu_{r}$ was the coefficient of friction of the regolith (assumed to be similar to sand or 0.4), and $d_{r s}$ was the distance the scoop came in contact with the regolith (assumed $1 \mathrm{~m}$ ). The carbothermal reactor the height $\left(h_{r}\right)$ was $1.37 \mathrm{~m}$ ) (Ref. 10) and $h_{r s}$ was the height of the extending belt scoop (assumed $1 \mathrm{~m}$ ). The second step was to separate out the large particles of regolith by using a vibrating screen. The largest particle size $\left(d_{i}\right)$ was assumed to be identical to the particle size required for the hydrogen reduction process, which was determined to be $0.84 \mathrm{~mm}$. The power required to operate the vibrating screen can be determined by Equation (12).

After being screened, the regolith would then be processed. Inside the system, several augers and actuators were used to move the machine components and/or the regolith. $50 \mathrm{~W}$ were assumed as the power requirements for the machine movements. This should provide some margin based on the current power requirement estimates. The ORBITEC module produced regolith melts that were approximately $7.5 \mathrm{~cm}$ across and were roughly hemi-spherical (Ref. 10). The number of melts per hour could be determined based on the volume of each melt, the flow rate of the regolith, and the density of the regolith, which was approximately $1000 \mathrm{~kg} / \mathrm{m}^{3}$. This number was calculated as 13.8 per hour, and dictates how much time could be allotted for each melt to maintain the yearly oxygen production quota. The thermal power needed to heat the regolith to the desired temperature $\left(Q_{h}\right)$ could be found by Equation (32):

$$
Q_{h}=n_{m} \rho_{r} c_{p} v_{m} \frac{\left(T_{m}-T_{r}\right)}{t_{m}}
$$

Where $n_{m}$ was the number of melts being processed in the module, $\rho_{r}$ was the density of the regolith, $c_{p}$ was the specific heat (1646.8 J/kg*K based on the desired temperature for the reaction), $v_{m}$ was the volume of a single melt, $T_{m}$ was the temperature of the melt, $T_{r}$ was the temperature of the regolith, and $t_{m}$ was the time allowed for the regolith to reach the desired temperature. The desired temperature of the melt was $1900{ }^{\circ} \mathrm{C}$ (Ref. 10). The temperature of the regolith was the same as the temperature on the surface of the moon during the day or $384 \mathrm{~K}$ (Refs. 1 and 7). The relation for the specific heat of the regolith came from a curve fit of experimental data on the regolith (Ref. 5). This relationship is described by Equation (1).

The regolith melts are heated in a bed of regolith that utilizes the surrounding regolith as insulation (Fig. 13). Due to this thick layer of insulation, it was assumed that no heat was lost through the regolith. This structure limits radiation losses to the surface of the regolith.

The equation for radiation heat transfer was utilized along with the number of regolith melts being processed. Since the processed regolith needed to be solidified before it could be extracted, it was assumed that the melt would be held at the processing temperature half of the time and allowed to solidify the other half. Equation (33) was used to calculate heat losses through radiation $\left(Q_{l}\right)$ :

$$
Q_{l}=\frac{1}{2} A_{S} \sigma n_{m} \frac{\left(T_{m}-T_{S}\right)}{\left(\frac{1}{\varepsilon_{c}}+\frac{2 n_{l}}{\varepsilon_{i}}-n_{l}+1\right)}
$$

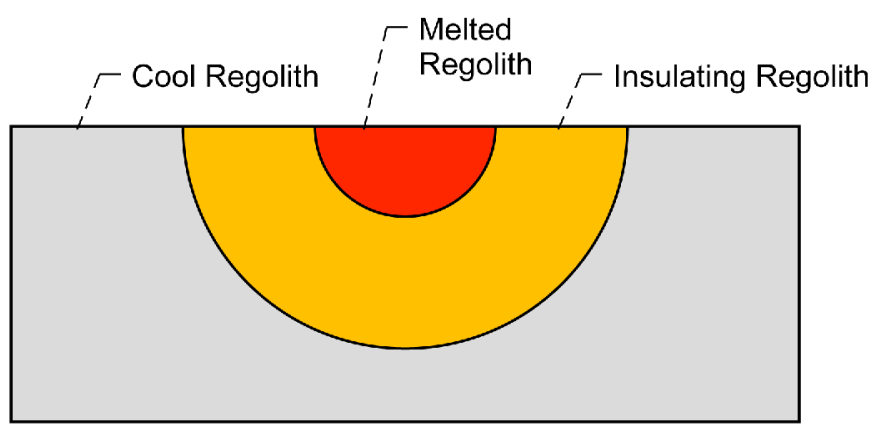

Figure 13.-Diagram of Regolith melt insulated by surrounding Regolith. 
Where $A_{S}$ was the surface area exposed to radiation loses, $\sigma$ was the Stefan-Boltzman constant with a value of $5.67 \times 10^{-8} \mathrm{~W} / \mathrm{m}^{2} \mathrm{~K}, T_{s}$ was the temperature of the surrounding (assumed to be $270 \mathrm{~K}$ ), $\varepsilon_{c}$ was the emissivity of the container of the reactor (assumed to be chromium with a value of 0.14 ), $\varepsilon_{i}$ was the emissivity of the insulation material around the reactor (assumed to be nickel with a value of 0.17 ), and $n_{l}$ was the number of insulation layers (assumed 50). A well-insulated system would only require an estimated 1 or $2 \mathrm{~W}$ to keep the system at daytime temperatures. Other than radiation loses, the regolith would also absorb heat due to the heat of reaction of the reactants $\left(Q_{r}\right)$. This was determined by summing the heats of reaction for each of the substances depending on the percentage of each of the substances in the regolith (discussed further in the next section). The next step in the process was to have the reactant gasses enter the methanation reactor (combining $\mathrm{CO}$ and $\mathrm{H}_{2}$ to form $\mathrm{CH}_{4}$ and $\mathrm{H}_{2} \mathrm{O}$ ) as well as clean any impurities contained within the gases. It was assumed the energy produced in the methanation reaction met the energy requirement for the clean-up modules. The final power requirement was the electrolyzer $\left(P_{e}\right)$ for the $\mathrm{H}_{2} \mathrm{O}$ to produce $\mathrm{H}_{2}$ and $\mathrm{O}_{2}$. This was calculated by using the $3520 \mathrm{~W} / \mathrm{kg} / \mathrm{h}$ theoretical power needed to separate the components and the efficiency of the electrolyzer, which was assumed to be 0.72 , (Ref. 7) see Equation (23). The total thermal and electrical power requirements were determined by summing the individual component power requirements discussed above.

\section{Results of Sizing for Carbothermal Reduction}

Based on the desired $1000 \mathrm{~kg} /$ year oxygen production rate with an assumed 15 percent yield, the mass flow rate of the regolith was determined to be approximately $1.52 \mathrm{~kg} / \mathrm{h}$. This flow rate was used to determine the power requirements of each component of the system based on one melt being processed at a time. The thermal power requirements can be found in Table 4, and the electrical power requirements can be found in Table 5. A visual representation of the breakdown of power requirements (both thermal and electrical) can be seen in Figures 14 and 15.

TABLE 4.-BREAKDOWN OF THERMAL POWER REQUIREMENTS

\begin{tabular}{|l|c|}
\hline \multicolumn{1}{|c|}{ System } & Power, \\
& W \\
\hline Radiation heat loss & 272.5 \\
\hline Power to heat the regolith & 2491.2 \\
\hline Total heat of reaction & 5555.5 \\
\hline Total thermal power & 8319.2 \\
\hline
\end{tabular}

TABLE 5.-BREAKDOWN OF ELECTRICAL POWER REQUIREMENTS

\begin{tabular}{|l|c|}
\hline \multicolumn{1}{|c|}{ System } & $\begin{array}{c}\text { Power, } \\
\text { W }\end{array}$ \\
\hline Power to lift the regolith & 0.0011 \\
\hline Power to scoop the regolith & 0.0003 \\
\hline Power of the vibrating screen & 0.3651 \\
\hline Power of the actuators and augers & 50.00 \\
\hline Power of the electrolyzer & 1754.1 \\
\hline Total electrical power & 1804.4 \\
\hline
\end{tabular}


- Heat loss to surroundings

- Regolith heating

Heat of reaction

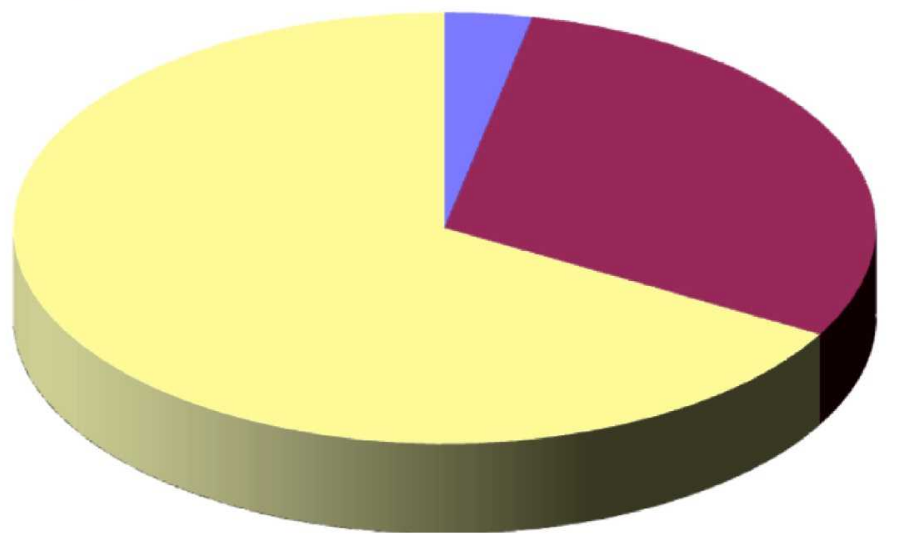

Figure 14.-Breakdown of thermal power requirements for carbothermal reaction.

- Operate electrolyzer

- Process Regolith

(lift, scoop, vibrate, separate)

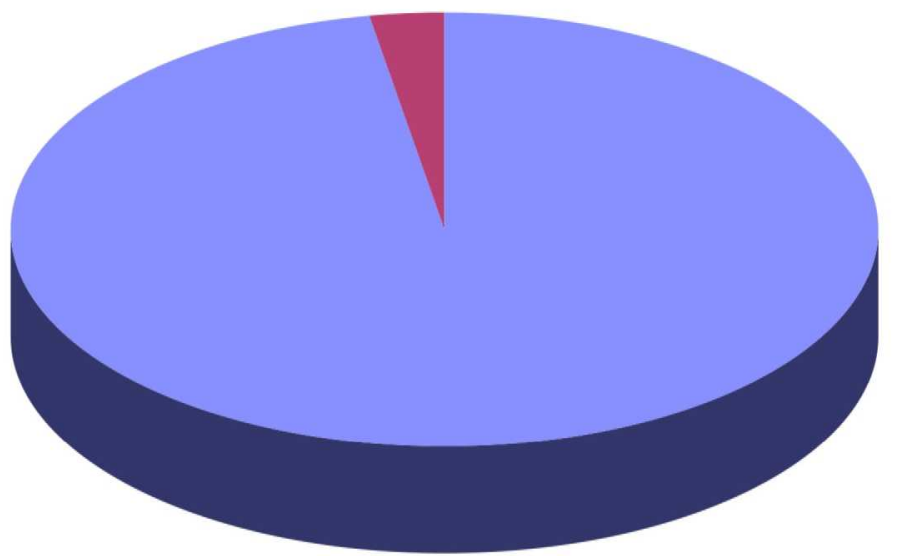

Figure 15.-Breakdown of electrical power requirements for carbothermal reaction. 
To determine the total heat of reaction, each compound in Table 1 was analyzed for their individual heats of reaction with $\mathrm{CH}_{4}$. These reactions were assumed to be at room temperature, since the difference equated to less than 0.3 percent for $\mathrm{SiO}_{2}$ reacting at 1900 and $25^{\circ} \mathrm{C}$ (room temperature). The heats of reaction were calculated to be approximately 841 and $839 \mathrm{~kJ} / \mathrm{mol} \mathrm{SiO}_{2}$, respectively. The calculated heats of reaction for each of the major substances are shown in Table 6.

The total heat of reaction depended on the amount of each substance (in Table 6) that was present in the regolith (the percent composition can be found in Table 1). The total estimated heats of reaction for the Highland and Mare regions were 5,556 and 5,135 W, respectively. To ensure that the calculations did not bias one area over the other, $5,556 \mathrm{~W}$ was used for the total heat of reaction.

The calculated power requirements above were based on the ORBITEC carbothermal regolith reduction module running one batch (melt) at a time. However, the module could run 7 melts (batches) simultaneously (Ref. 10). Since each melt had a specific size and the mass flow rate of the regolith needed to meet a specific value, the time allowed for each melt process could not exceed a specific value. It should also be noted that under certain cases the required process time could be unrealistic. The maximum time allowed for each melt under different numbers of simultaneous processes can be seen in Figure 16.

It was assumed that half the total amount of time would be spent on heating the regolith. However if more time was required, more modules could be simultaneously operated in order to maintain the desired production rate of $\mathrm{O}_{2}$. Also due to the additional melts, more thermal power would be required. Based on the increased thermal power for the additional melts being processed, the total power required for various numbers of melts can be seen in Figure 17.

TABLE 6. - HEAT OF REACTION FOR METAL OXIDE WITH $\mathrm{CH}_{4}$ TO PRODUCE CO AND H

\begin{tabular}{|l|c|}
\hline \multicolumn{1}{|c|}{ Reactant } & $\begin{array}{c}\text { Heats of reaction, } \\
\text { kJ/mol }\end{array}$ \\
\hline $\mathrm{SiO}_{2}$ & 838.84 \\
\hline $\mathrm{Al}_{2} \mathrm{O}_{3}$ & 1567.91 \\
\hline $\mathrm{FeO}$ & 236.07 \\
\hline $\mathrm{CaO}$ & 598.99 \\
\hline $\mathrm{MgO}$ & 565.67 \\
\hline $\mathrm{TiO}_{2}$ & 872.14 \\
\hline
\end{tabular}

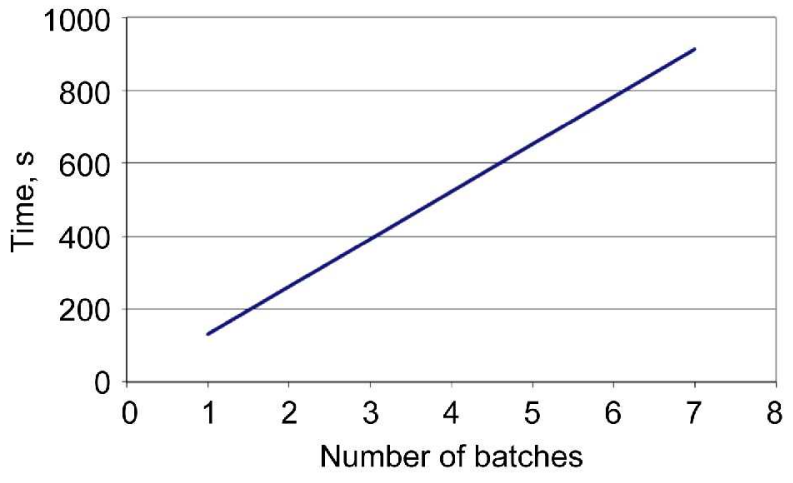

Figure 16.-Maximum time available to process each batch-dependent upon the amount of oxygen produced per year (1000 kg/year) and utilizing only one module.

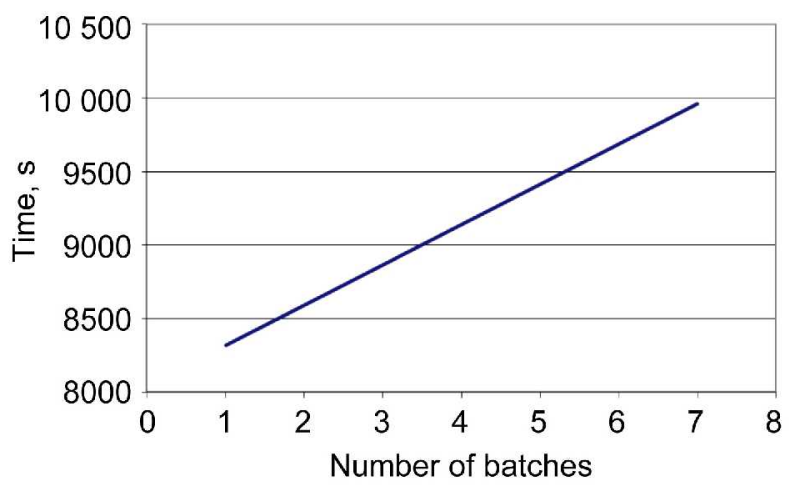

Figure 17.-Total thermal power requirements based on number of simultaneous batches using one module. 
The power consumption for the Carbothermal Reduction can be compared to the power consumption of the Hydrogen Reduction method. Using the scenario of only 1 melt operating at a time, the total power requirement for the carbothermal process came to $10,124 \mathrm{~W}$. With a solar intensity of $1307 \mathrm{~W} / \mathrm{m}^{2}$ (approximated solar intensity on July 9 th at $180^{\circ}$ ), a solar concentrator with an area of $7.81 \mathrm{~m}^{2}$ would be needed for a single melt; an area of $9.35 \mathrm{~m}^{2}$ would be needed for 7 melts, with radii of 3.15 and $3.45 \mathrm{~m}$, respectively. For the carbothermal system it was assumed that the electrical power needed to run the system would be provided by solar arrays. Table 7 shows a representative sampling of terrestrial rigid panel solar arrays along with the total area and mass needed for the arrays (based on the power output of each array and the total electrical power needed) (Ref. 11). The power consumption of the Hydrogen Reduction method was approximately 7,400 W. However, much of that power was used for the Stirling engine. Removing the heat required for the engine left a power requirement of approximately $3,718 \mathrm{~W}$ based on an equivalent $\mathrm{O}_{2}$ mass flow rate.

TABLE 7.-REPRESENTATIVE TERRESTRIAL RIGID PANEL SOLAR ARRAY AREA AND MASS (REF. 11)

\begin{tabular}{|l|c|c|c|c|c|c|}
\hline & $\begin{array}{c}\text { Mass, } \\
\mathrm{kg}\end{array}$ & $\begin{array}{c}\text { Area, } \\
\mathrm{m}^{2}\end{array}$ & $\begin{array}{c}\text { Power, } \\
\mathrm{W}\end{array}$ & $\begin{array}{c}\text { Number } \\
\text { needed }\end{array}$ & $\begin{array}{c}\text { Total area, } \\
\mathrm{m}^{2}\end{array}$ & $\begin{array}{c}\text { Total mass, } \\
\mathrm{kg}\end{array}$ \\
\hline M55 & 5.5 & 0.43 & 55 & 32.8 & 14.0 & 181.9 \\
\hline SX-170B & 15.0 & 1.26 & 170 & 10.6 & 13.4 & 159.2 \\
\hline ES-190-SL & 18.2 & 1.50 & 190 & 9.5 & 14.2 & 173.1 \\
\hline GEPV-200 & 17.7 & 1.44 & 200 & 9.0 & 13.0 & 160.0 \\
\hline 1KA-GSA & 13.7 & 0.95 & 60 & 30.1 & 28.6 & 412.0 \\
\hline KC130GT & 15.0 & 0.93 & 130 & 13.9 & 12.9 & 208.2 \\
\hline PV-MF170EB4 & 15.5 & 1.26 & 170 & 10.6 & 13.4 & 164.5 \\
\hline PW1650-165 & 18.0 & 1.36 & 165 & 10.9 & 14.9 & 196.8 \\
\hline HIP-205BA3 & 14.0 & 1.18 & 205 & 8.8 & 10.4 & 123.2 \\
\hline S-170-SPU & 15.5 & 1.26 & 170 & 10.6 & 13.4 & 164.5 \\
\hline ND-208U1 & 21.0 & 1.63 & 208 & 8.7 & 14.1 & 182.2 \\
\hline 175-PC & 17.3 & 1.32 & 175 & 10.3 & 13.6 & 178.1 \\
\hline SW165 & 15.0 & 1.30 & 165 & 10.9 & 14.3 & 164.0 \\
\hline STP170S & 15.5 & 1.28 & 170 & 10.6 & 13.6 & 164.5 \\
\hline SW160 & 20.0 & 1.30 & 160 & 11.3 & 14.7 & 225.6 \\
\hline Average & 15.8 & 1.23 & 160 & 13.2 & 14.6 & 190.5 \\
\hline
\end{tabular}

\section{Conclusions}

The results of the baseline system produced just under $0.6 \mathrm{~kg}$ of oxygen per hour with a mirror size of less than $5 \mathrm{~m}$ diameter. For a full 14-day mission, where the production plant is in continuous sunlight, approximately $195 \mathrm{~kg}$ of oxygen would be produced. This translates into a yearly production rate of approximately $2300 \mathrm{~kg}$ of oxygen. The system size should also enable it to be packaged into a single launch vehicle providing a system configuration that can be autonomously deployed and operated. If greater oxygen production rates are required the system can be scaled up, requiring a larger mirror size for operation. Another alternative is to consider these oxygen production systems as modular. If an increased rate of production is needed then two or more systems can be utilized.

As more detail is incorporated into the various components that make up the system, the sizing and oxygen production rates will likely change. However, the results produced by this analysis should be representative of the systems' potential. The analysis done demonstrated that more power would be required to produce $1000 \mathrm{~kg} / \mathrm{year}$ of oxygen using the carbothermal reduction method as compared to the hydrogen reduction method. However, there is the advantage of utilizing all of the regolith instead of just the ilmenite that is used for hydrogen reduction. Furthermore, a solar concentrator with a diameter less than $4 \mathrm{~m}$ could provide the thermal power needed. The electrical power $(1804 \mathrm{~W})$ would be provided from solar panels.

An integrated solar dynamic/Stirling heat engine system or a hybrid solar/photovoltaic are excellent candidates for powering a lunar oxygen production facility utilizing respectively, either hydrogen reduction or carbothermal reduction technologies. The flight system should provide for an efficient, compact design that can be designed as an integrated stand-alone unit. This would enable the system to be utilized for a number of different applications from a main base to a remote camp. It also can provide a basis for a standardized, modular oxygen production system design. 


\section{References}

1. Heiken, G., Vaniman, D., and French, B.M. (eds.), Lunar Sourcebook, Cambridge Univ. Press, Cambridge, UK, 1991.

2. Hepp, A.F., Linne, D.L., Landis, G.A., Wadel, M.F., and Colvin, J.E., "Production and Use of Metals and Oxygen for Lunar Propulsion," Journal of Propulsion and Power, vol. 10, no. 6, 1994, pp. 834-840 and references therein.

3. U.S. Naval Research Laboratory, "The Clementine Mission," web site [archival online database], URL: http://www.cmf.nrl.navy.mil/clementine/clementine.html [cited 15 July 2006].

4. Christianson, E.L., "Conceptual Design of a Lunar Oxygen Pilot Plant Lunar Base Systems Study (LBSS)," Eagle Engineering, Inc. Report 88-182, NASA Contract NAS9-17878, 1988.

5. Colozza, A.J., "Analysis of Lunar Regolith Thermal Energy Storage," NASA CR-189073, 1991.

6. Rauschenbach, H.S., "Solar Cell Array Design Handbook, Volume 1," NASA CR-149364, 1976.

7. Colozza, A.J. and Wong, W.A., "Evaluation of a Stirling Solar Dynamic System for Lunar Oxygen Production," NASA/TM-2006-2143603, 2006.

8. Colozza, A.J., "Hydrogen Storage for Aircraft Applications Overview," NASA/CR - 2002-211867, 2002.

9. Weiss, N.L. (ed.), SME Mineral Processing Handbook, Volumes 1 and 2, American Institute of Mining, Metallurgical and Petroleum Engineers, New York, NY, 1985.

10. Gustafson, R.J., White, B.C, and Fidler, M.J., "Demonstrating Lunar Oxygen Production With the Carbothermal Regolith Reduction Process," 47th AIAA Aerospace Sciences Meeting, AIAA-2009-663, Washington, DC, 2009.

11. Colozza, A.J., "Power System Mass Analysis for Hydrogen Reduction Oxygen Production on the Lunar Surface," NASA/CR-2009-215504, 2009. 


\begin{tabular}{|c|c|c|}
\hline \multicolumn{2}{|c|}{ REPORT DOCUMENTATION PAGE } & $\begin{array}{l}\text { Form Approved } \\
\text { OMB No. 0704-0188 }\end{array}$ \\
\hline \multicolumn{3}{|c|}{ 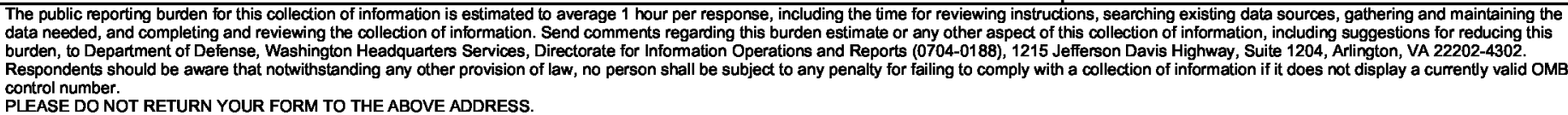 } \\
\hline $\begin{array}{l}\text { 1. REPORT DATE (DD-MM-YYYY) } \\
01-04-2010\end{array}$ & $\begin{array}{l}\text { 2. REPORT TYPE } \\
\text { Technical Memorandum }\end{array}$ & 3. DATES COVERED (From - To) \\
\hline \multirow{3}{*}{\multicolumn{2}{|c|}{$\begin{array}{l}\text { 4. TITLE AND SUBTITLE } \\
\text { Solar Energy Systems for Lunar Oxygen Generation }\end{array}$}} & 5a. CONTRACT NUMBER \\
\hline & & 5b. GRANT NUMBER \\
\hline & & 5c. PROGRAM ELEMENT NUMBER \\
\hline \multirow{3}{*}{\multicolumn{2}{|c|}{$\begin{array}{l}\text { 6. AUTHOR(S) } \\
\text { Colozza, Anthony, J.; Heller, Richard, S.; Wong, Wayne, A.; Hepp, Aloysius, F. }\end{array}$}} & 5d. PROJECT NUMBER \\
\hline & & 5e. TASK NUMBER \\
\hline & & $\begin{array}{l}\text { 5f. WORK UNIT NUMBER } \\
\text { WBS 387498.01.04.02.05.03 }\end{array}$ \\
\hline \multicolumn{2}{|c|}{$\begin{array}{l}\text { 7. PERFORMING ORGANIZATION NAME(S) AND ADDRESS(ES) } \\
\text { National Aeronautics and Space Administration } \\
\text { John H. Glenn Research Center at Lewis Field } \\
\text { Cleveland, Ohio 44135-3191 }\end{array}$} & $\begin{array}{l}\text { 8. PERFORMING ORGANIZATION } \\
\text { REPORT NUMBER } \\
\text { E-17201 }\end{array}$ \\
\hline \multirow{2}{*}{\multicolumn{2}{|c|}{$\begin{array}{l}\text { 9. SPONSORING/MONITORING AGENCY NAME(S) AND ADDRESS(ES) } \\
\text { National Aeronautics and Space Administration } \\
\text { Washington, DC 20546-0001 }\end{array}$}} & $\begin{array}{l}\text { 10. SPONSORING/MONITOR'S } \\
\text { ACRONYM(S) } \\
\text { NASA }\end{array}$ \\
\hline & & $\begin{array}{l}\text { 11. SPONSORING/MONITORING } \\
\text { REPORT NUMBER } \\
\text { NASA/TM-2010-216219 }\end{array}$ \\
\hline \multicolumn{3}{|c|}{$\begin{array}{l}\text { 12. DISTRIBUTION/AVAILABILITY STATEMENT } \\
\text { Unclassified-Unlimited } \\
\text { Subject Categories: } 20 \text { and } 44 \\
\text { Available electronically at http://gltrs.grc.nasa.gov } \\
\text { This publication is available from the NASA Center for AeroSpace Information, 443-757-5802 }\end{array}$} \\
\hline
\end{tabular}

\section{SUPPLEMENTARY NOTES}

\section{ABSTRACT}

An evaluation of several solar concentrator-based systems for producing oxygen from lunar regolith was performed. The systems utilize a solar concentrator mirror to provide thermal energy for the oxygen production process. Thermal energy to power a Stirling heat engine and photovoltaics are compared for the production of electricity. The electricity produced is utilized to operate the equipment needed in the oxygen production process. The initial oxygen production method utilized in the analysis is hydrogen reduction of ilmenite. Utilizing this method of oxygen production a baseline system design was produced. This baseline system had an oxygen production rate of $0.6 \mathrm{~kg} / \mathrm{hr}$ with a concentrator mirror size of $5 \mathrm{~m}$. Variations were performed on the baseline design to show how changes in the system size and process (rate) affected the oxygen production rate. An evaluation of the power requirements for a carbothermal lunar regolith reduction reactor has also been conducted. The reactor had a total power requirement between 8,320 to $9,961 \mathrm{~W}$ when producing $1000 \mathrm{~kg} / \mathrm{year}$ of oxygen. The solar concentrator used to provide the thermal power (over 82 percent of the total energy requirement) would have a diameter of less than 4 $\mathrm{m}$.

\section{SUBJECT TERMS}

Solar concentrators; Stirling cycle; Oxygen production; Photovoltaic conversion; Lunar surface; Regolith

\begin{tabular}{|c|c|c|c|c|c|}
\hline \multicolumn{3}{|c|}{ 16. SECURITY CLASSIFICATION OF: } & \multirow{2}{*}{$\begin{array}{l}\text { 17. LIMITATION OF } \\
\text { ABSTRACT } \\
\text { UU }\end{array}$} & \multirow{2}{*}{$\begin{array}{l}\text { 18. NUMBER } \\
\text { OF } \\
\text { PAGES } \\
26\end{array}$} & \multirow{2}{*}{$\begin{array}{l}\text { 19a. NAME OF RESPONSIBLE PERSON } \\
\text { STI Help Desk (email:help@sti.nasa.gov) } \\
\text { 19b. TELEPHONE NUMBER (include area code) } \\
\text { 443-757-5802 }\end{array}$} \\
\hline $\begin{array}{l}\text { a. REPORT } \\
U\end{array}$ & $\begin{array}{l}\text { b. ABSTRACT } \\
U\end{array}$ & $\begin{array}{l}\text { c. THIS } \\
\text { PAGE } \\
\text { U }\end{array}$ & & & \\
\hline
\end{tabular}



